\title{
Consideration of Impact Factors on Data Acquisition for Ocean Radar with VHF Band
}

\author{
Takumi Yoshii $^{\# 1}$, Shin'ich Sakai ${ }^{\# 2}$, Takaki Tsubono ${ }^{\# 3}$, Masafumi Matsuyama ${ }^{\# 4}$, \\ Akihide Tada ${ }^{* 5}$, Takehiro Nakamura ${ }^{* 6}$ \\ ${ }^{\#}$ Central Research Institute of Electric Power Industry \\ 1646, Abiko, Abiko, Chiba, 270-1194, Japan \\ ${ }^{1}$ takumi@criepi.denken.or.jp \\ s-sakai@criepi.denken.or.jp \\ tsubono@criepi.denken.or.jp \\ ${ }^{4}$ matsu@criepi.denken.or.jp \\ *Faculty of Engineering \& Faculty of Environmental Studies, Nagasaki University \\ 1-14, Bunkyo-machi, Nagasaki, 852-8521, Japan \\ 5ada@civil.nagasaki-u.ac.jp \\ ${ }^{6}$ tak-nak@nagasaki-u.ac.jp
}

\begin{abstract}
An ocean radar with a VHF band is a useful tool for surveying coastal currents in a wide area. We have conducted a field observation of currents in Ariake Bay, the large inner sea located in the western part of Japan. Although the number of valid data acquired (hereafter, data acquisition) varies temporally and spatially, the mechanism of such variation is not yet well understood. Our aim in this study is to investigate the impact factor affecting data acquisition through field observations of current, salinity and wind in Ariake Bay. As a result, the data acquisition and the maximum measurement distance of the radar decreased owing to the decreases in salinity and wind speed. After receiving much rainfall, the data acquisition decreased rapidly in accordance with the decrease in surface salinity influenced by run-off from adjacent rivers and a flood control dike. Also, when wind speed became less than $2 \mathrm{~m} / \mathrm{s}$, the intensity of the signals received was not sufficient for the detection of current velocity. In conclusion, salinity and wind speed are important factors for steady-current observation using ocean radars.
\end{abstract}

\section{INTRODUCTION}

In this study, we investigate the impact factors affecting the acquisition of valid data for surface current measurement using a digital beam forming (DBF) ocean radar with a VHF band through field observations in Ariake Bay, a large inner sea located in the western part of Japan.

Recent interest related in oceanic environments has let researchers to extensively study the mechanism of current field and water quality by field observations and numerical simulations. We have conducted some field observations of surface currents using a DBF ocean radar with a VHF band in several bays and confirmed that the measurement using a radar has high accuracy, which indicates that a DBF ocean radar is useful for surveying wide current phenomenon in oceans and for coastal protection against coastal disasters such as oil spills (e.g. [1], [2]). In this study, we have conducted a long term observation of surface currents in Ariake Bay to find out the mechanism of red tide occurrence. However, the data acquisition of the DBF ocean radar varied temporally and spatially.

Referring to the theory, the receiving power is a function of conductivity, permittivity, wave spectrum, and others. Conductivity and permittivity are generally assumed as steady values. In addition, the Bragg scattering wave exists under a fully developed condition in oceans. Daniel M.F et al. [3] examined the effect of salinity on the surface current measurement using ocean radar with a HF band in freshwater lakes and found that the maximum observational range is much narrower than that in oceans because of the large propagation loss of radio waves owing to small conductivity related to low salinity. In addition, many researchers have attempted to calculate the wave spectrum by using the dependence of the 1st- and 2nd-order scatterings of the Doppler spectrum on wave height under the assumption of constant conductivities and permittivities. The effect of salinity on data acquisition in the oceans is not yet fully understood. In order to conduct steady field observation, it is important to understand factors that affect data acquisition in the ocean radar observation.

The aim of the present work has been the investigation of impact factors on the data acquisition for surface current measurement using a DBF ocean radar with a VHF band through field observations in Ariake Bay. To examine the effects of salinity and wind speed on data acquisition, we conducted salinity and wind speed observations in Ariake Bay. We researched the daily and sudden variations of data acquisition with these factors. In Chapter II, we describe the specifications of the DBF ocean radar and the oceanic characteristics of Ariake Bay. In Chapter III, we discuss effects of the surface salinity and wind speed on data acquisition, and examine the relationship of the daily cyclic variation of the data acquisition with the $\mathrm{M}_{2}$ tide. In Chapter $\mathrm{IV}$, we summarise the conclusions drawn from our results. 

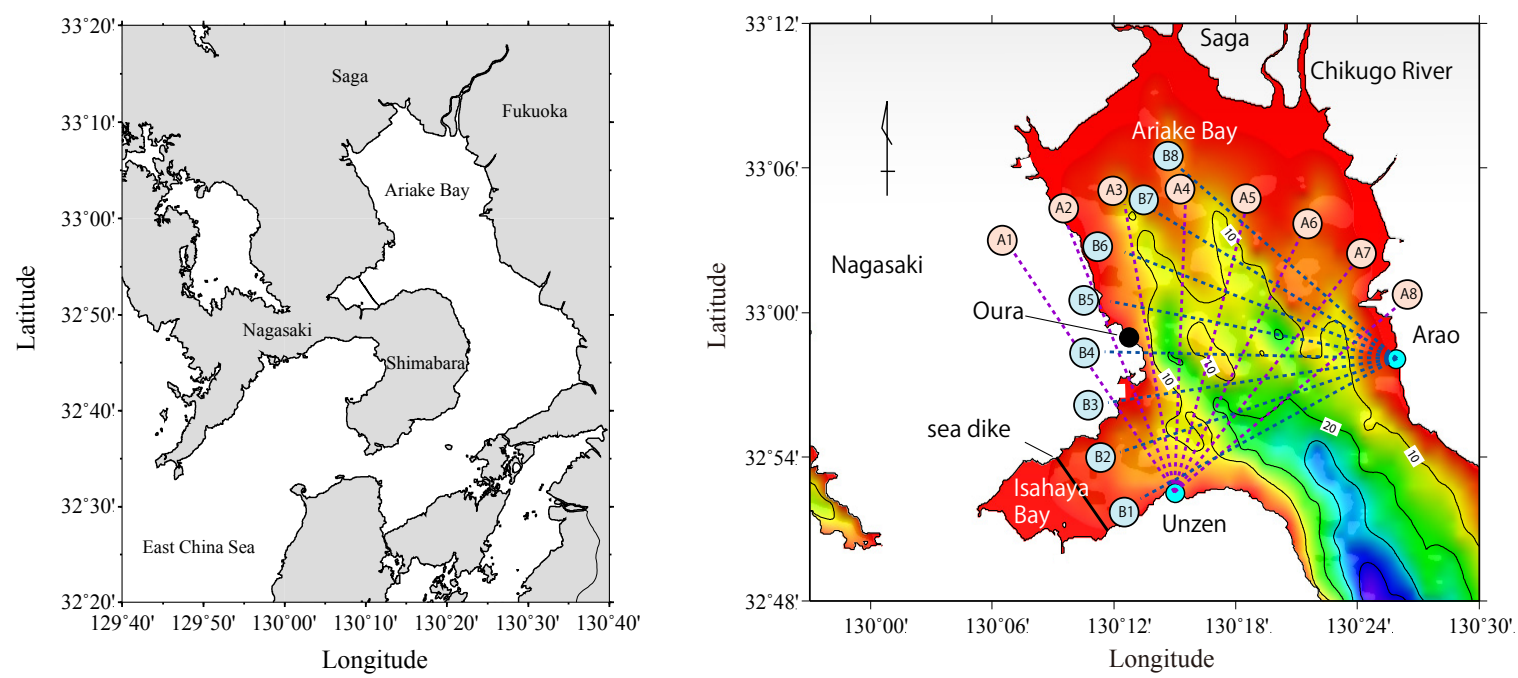

Fig. 1. Site locations (blue circle), observation area (observable beam lines are shown by broken lines), and sea bottom topography. Ariake Bay is heavily closed by Shimabara peninsula and nearly isolated from broad ocean. The observation of tide is conducted at Oura. There are tidal flats at the front of Arao.

\section{OBSERVATION}

\section{A. DBF Ocean Radar equipment}

The DBF ocean radar uses VHF radio waves of $41.9 \mathrm{MHz}$ central frequency with a sweeping range of $300 \mathrm{KHz}$. It was confirmed by the field tests described in [1], [2] that the DBF ocean radar can detect the surface current velocities of the sea with a high resolution of about $2 \mathrm{~cm} / \mathrm{s}$ within a radius of about $25 \mathrm{~km}$ at $0.5 \mathrm{~km}$ grid intervals. The DBF ocean radar is composed of one transmission antenna and eight receiving antennae. Doppler spectra in particular directions are formed by the digital beam forming method in the signal processing stage. The wavelength of Bragg scatter is approximately 3.5 $\mathrm{m}$. The radial components of surface currents are calculated from the Doppler spectrum by the Automatic Estimation Method developed in [4].

\section{B. Observant Description and Environment Conditions}

Ariake Bay is located on the Kyushu Island in west part of Japan. Fig. 1 shows the location of Ariake bay and the radar observational area. The DBF ocean radars were installed on the coasts of Unzen and Arao around Ariake Bay, and surface current observation was conducted from June 14, 2006 until November 1, 2007. Wind meters and rain gages were also installed close to each radar site, and we collected data every 10 minutes. Wind speed and wind direction were measured 3 $\mathrm{m}$ above the ground, approximately $8-10 \mathrm{~m}$ above the water surface. Tide data were recorded every hour at Oura by the Japan Meteorological Agency [6].

Ariake bay has a great tidal range of $\sim 6 \mathrm{~m}$ at the maximum and huge tidal flats. There are tidal flats in front of the Arao site but not at the Unzen site. The amount of run-off of the Chikugo River, located northeast of Ariake bay, is about 40 $\mathrm{m}^{3} / \mathrm{s}$ under normal condition, but after a heavy rainfall, for example, during the approach of a typhoon, the amount of run-off reaches $5000 \mathrm{~m}^{3} / \mathrm{s}$. Additionally, Isahaya Bay has a sea dike to prevent sea water from damaging the reclaimed

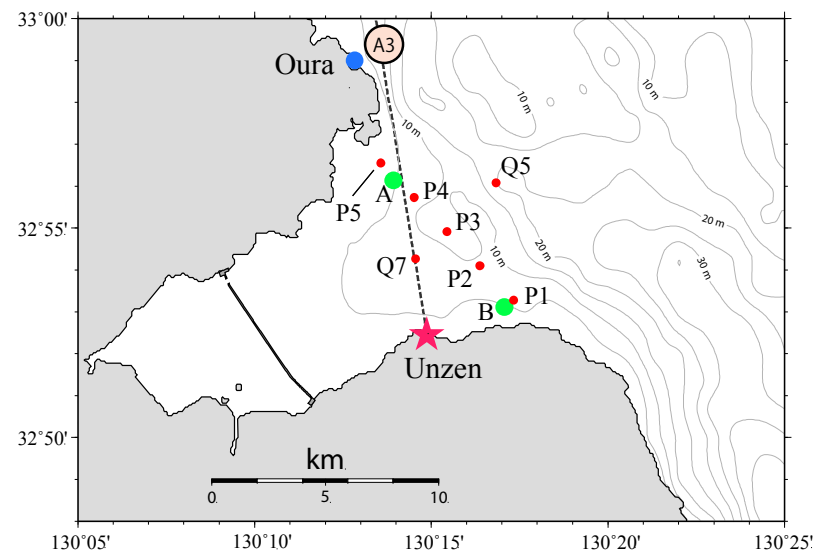

Fig. 2. The stations where the water qualities were observed. We conducted continuous observation at green points, and intermittent observation at red points

land, and discharges pooled water in the dike only after low tide.

Fig. 2 shows the stations where we observed water quality using CTD. At stations A and B, we continuously observed salinity and water temperature at $1 \mathrm{~m}$ depth from June 22 to August 7, 2007. At stations P1-P5, Q5, and Q7, we measured the vertical profiles of water quality on August 2, and October 8, 2006, and on August 12, and October 26, 2007.

\section{RESULTS OF OBSERVATION}

\section{A. Effect of Surface Salinity}

In the bay, which is heavily closed, an increasing amount of run-off of the river located in the bay may decrease surface salinity because of its low capability for water exchange. It may affect data acquisition. In the observation period, we could observe surface salinity during the approach of a typhoon. Fig. 3 shows the variations in the numbers of radial currents along beam lines at Unzen and Arao, the flow of the 
Chikugo River observed at Senoshita about $25 \mathrm{~km}$ upstream of the river mouth, the salinities of stations A and B, and tide at Oura from July 2 to July 14, 2007.

Under normal condition, the surface salinity was about 32 psu and the number of detected radial currents was about 300350 per one observation. After July 5, surface salinity decreased to approximately 20-25 psu and maintained the same value for one and a half days. Following a decrease in surface salinity, the numbers of detected radial currents decreased to about 250 . This decrease in surface salinity was caused by the increase in the amount of run-off of the Chikugo River on July 4. There were the time lags of about one-half days between the river run-off and the variation in surface salinity. We thought that the time lag was caused by the great tide in Ariake Bay. During high tide, freshwater were roll backed to the back of the bay by flood current. Conversely, at low water the fresh water diffused widely with ebb current.

On Jul 7, typhoon No.5 approached the Kyushu Island, and where it heavily rained in a wide ranging area. After the typhoon passed through the observational area, the amount of run-off of Chikugo River increased to approximately 5,000 $\mathrm{m}^{3} / \mathrm{s}$. Consequently, surface salinity decreased to less than 10 psu and the numbers of detected radial currents markedly decreased at the same time. The decrease in the numbers of detected radial currents was maintained for 2 days. On July 10 , surface salinity recovered temporally as influenced by strong wind of approximately $5 \mathrm{~m} / \mathrm{s}$, which mixed the water and broke the salt wedge. The numbers of radial currents at Unzen followed this temporally recovery of salinity. These results indicate that the observational condition is very sensitive to surface salinity.

Fig. 4 shows a scatter plot between the salinity at station A and the signal intensity of 1 st-order scattering at the nearest point of station A. Signal intensity was calculated by averaging the signal intensity of 1 st-order scattering from the range of $6 \mathrm{~km}$ to $8 \mathrm{~km}$ of the beam A3 to take the range of the beam into consideration. In the Doppler spectrum, two 1storder scatterings appear caused by radially approaching waves and radially receding waves. In this analysis, we used the
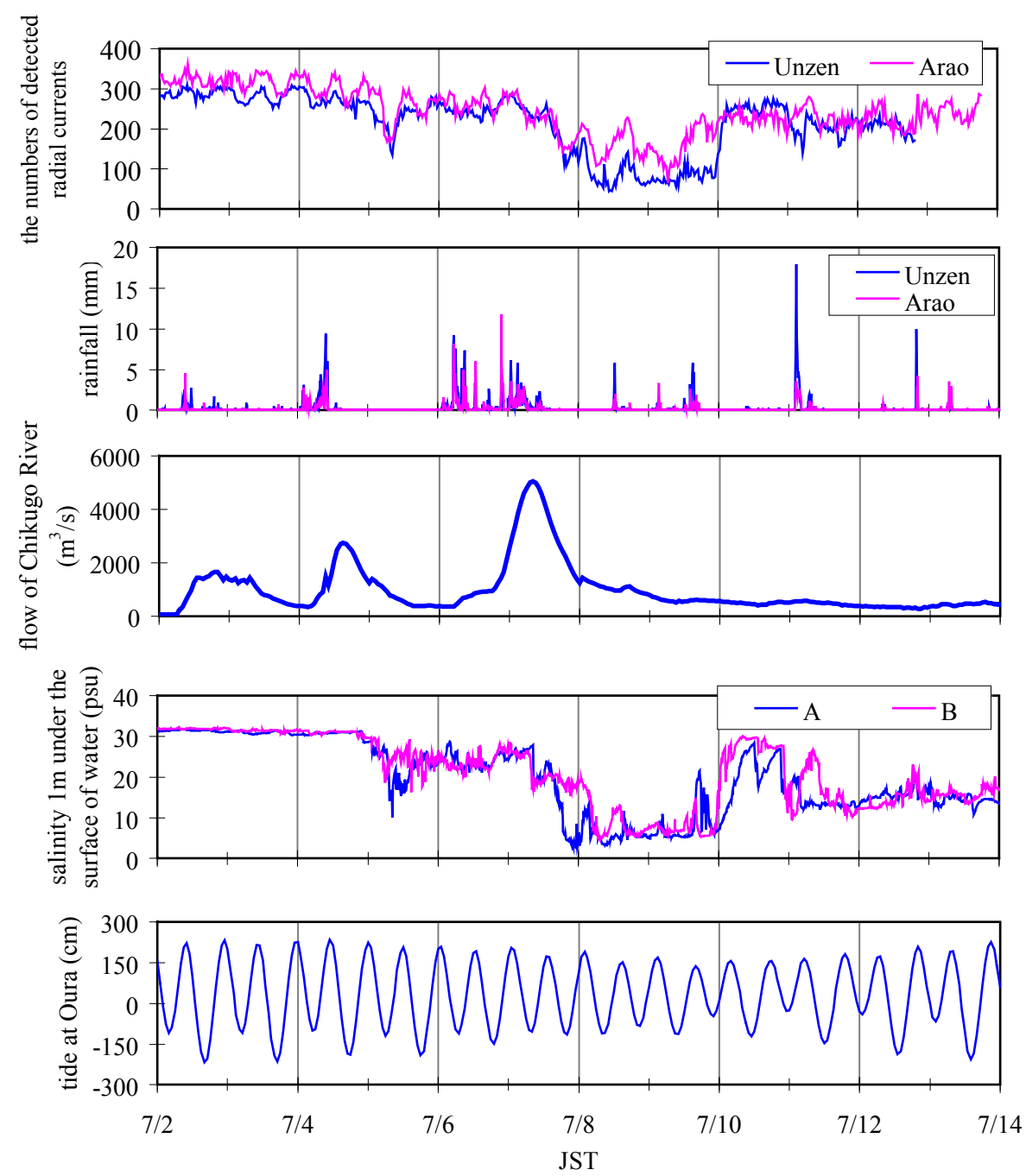

Fig. 3. The variations in the numbers of detected radial currents, the rainfalls observed at the each radar sites, the flow of Chikugo River observed about 25 $\mathrm{km}$ upstream of the river mouth, the salinity $1 \mathrm{~m}$ under the surface of water, and tide at Oura are shown. 


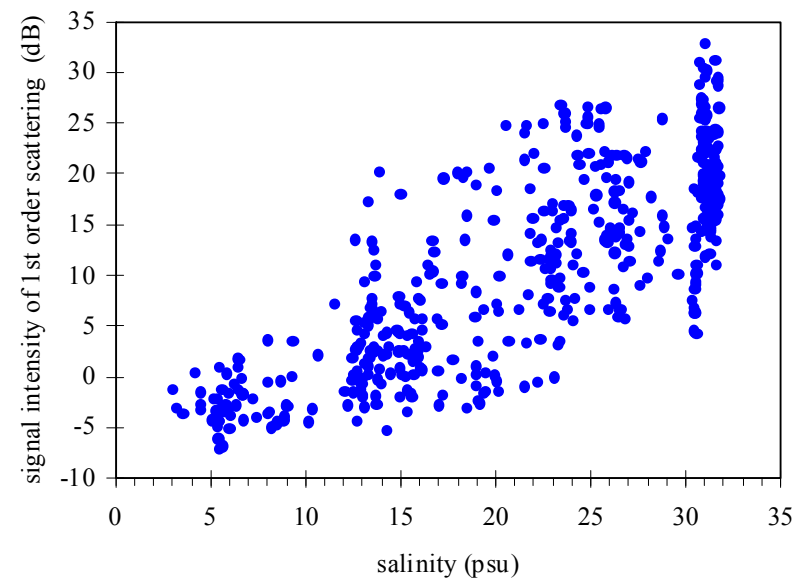

Fig. 4. Scattering plot between the salinity observed at station A and the signal intensity of 1 st-order scattering at the nearest point of station A. The signal intensity varies linearly with the salinity. The wide scattering of intensity might be caused by the wind speed.

largest value of two peaks. Fig. 4 shows that signal intensity was proportional to salinity. It indicates that the salinity is very-important factor on observation. In the low salinity condition, the observation range becomes narrow. The data spread in Fig. 4 might be caused by difference in wind speed.

From these results, we conclude that data acquisition significantly depends on surface salinity. The signal intensity of 1st-order scattering decreases owing to the decrease in salinity. Under lower salinity condition, the observation range becomes narrower. This result is the same as the observational results in [3] for fresh lake obtained with HF band. Additionally, we confirmed that the observational condition varies quickly with a variation in surface salinity in the oceans.

\section{B. Effect of Wind}

Ariake Bay is topographically isolated from the broad ocean, East China Sea, which prevents wave propagation from broad ocean. Thus wind is the most important factor in wave generation in Ariake Bay. It is known that the 1st-order scattering intensity of Doppler spectrum is influenced by the development of ocean waves with a frequency that is twofold that of the radar. Therefore, a low-wind condition would lead to the situation of the 1st-order scattering intensity of the Doppler spectrum, which is too small for detecting the current velocity.

Fig. 5 shows the variation in the number of detected radial currents, and in the wind speeds and wind directions observed at both radar sites from February 27 until March 8, 2007. Wind direction was defined as the clockwise angle from the north direction. From March 2 to March 4, 2007, the wind speed was very low, which resembled sea breeze judging from its cyclic variation. At the midnights during the period, the number of detected radial currents showed a sharp drop and the wind speeds were less than $1 \mathrm{~m} / \mathrm{s}$. With an increase in wind speed over $1 \mathrm{~m} / \mathrm{s}$, the number of radial currents recovered. When similar sharp drops were found in other periods, the wind speeds were less than $1 \mathrm{~m} / \mathrm{s}$ (not shown). The recoveries of the number of detected radial currents were also sensitive to wind speed, and increased quickly following an increase in wind speed. Adversely, a decrease in the number of detected radial currents occurred when low-wind condition continued for more than an hour. Thus, a specific wave that generates Bragg scattering grows rapidly and
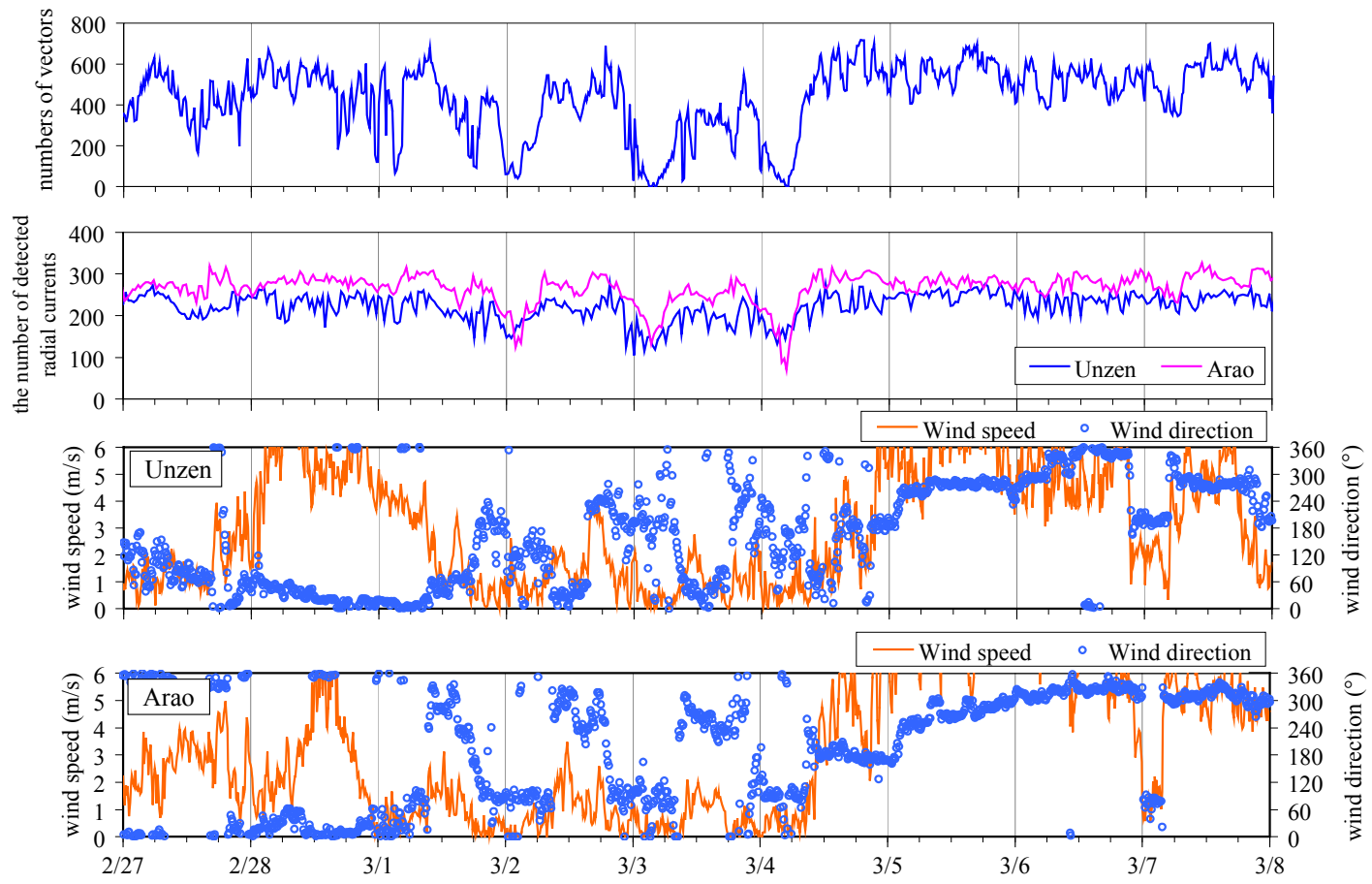

Fig. 5. The variation in the numbers of vectors, detected radial currents, wind speed and direction at Unzen and Arao. 

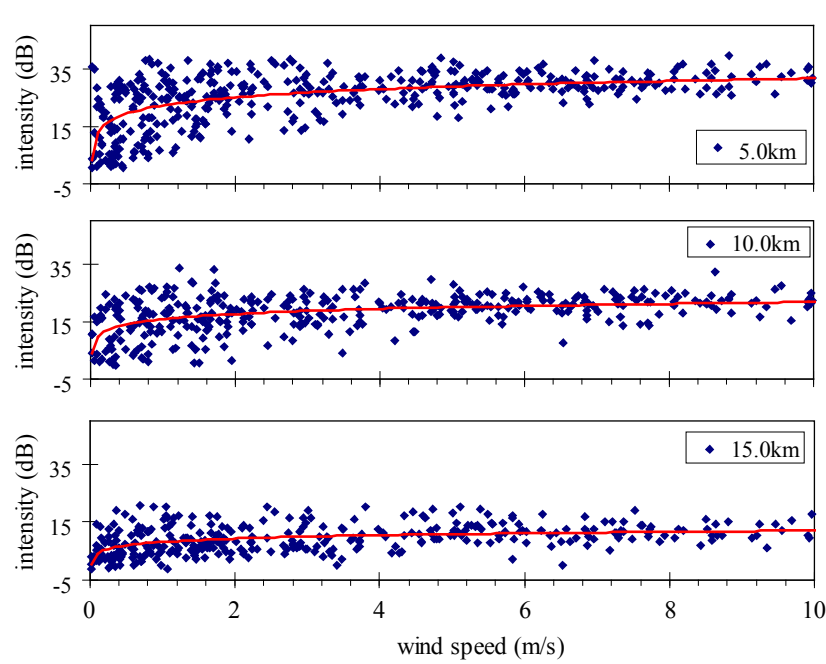

Fig. 6. The variations in 1st order scattering intensity of the beam A6 with the wind speed at Unzen. The intensity increased following the wind speed under $2 \mathrm{~m} / \mathrm{s}$, but changed little above that.

disappears within a few hours.

Next, we investigated the wind effect on the signal intensity of 1st-order scattering at different ranges in the same time period, as shown in Fig. 5. We chose the data of beam A6 to prevent the land effect on wind development. The intensities at the distance of $5.0 \mathrm{~km}, 10.0 \mathrm{~km}$, and $15.0 \mathrm{~km}$ are shown in Fig. 6. To grasp the trends of data, we also plot the logarithmic curves calculated by regression analysis. Fig. 6 indicates that the signal intensity increased with wind speed at a wind speed less than $2 \mathrm{~m} / \mathrm{s}$. In contrast, the signal intensity was sufficient to detect current at a wind speed of over $2 \mathrm{~m} / \mathrm{s}$. We investigated other beam lines, and found a drop of receiving intensity with a wind speed under $1 \mathrm{~m} / \mathrm{s}$ like that shown in Fig. 6 in all beam lines. Thus, it would appear that the drop in receiving intensity in the period shown in Fig. 5 was attributable mainly to drop of wind speed and not depend on the wind direction.
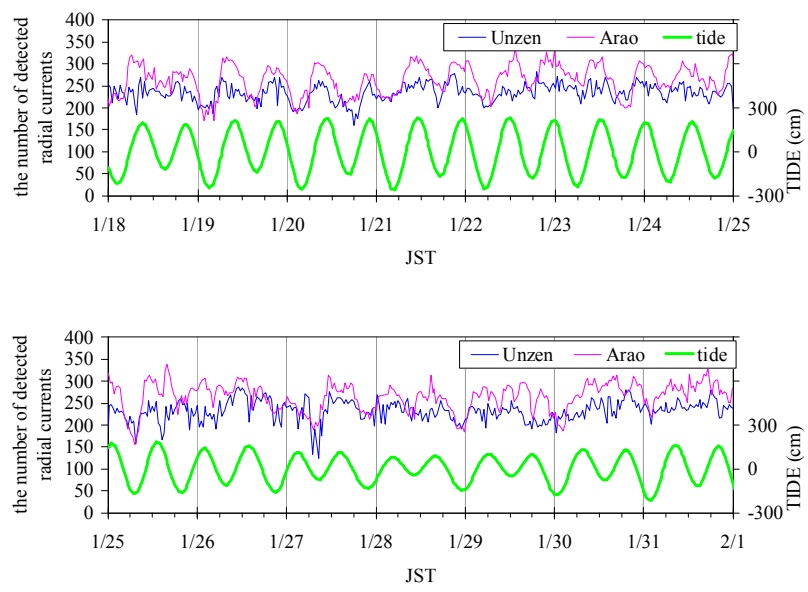

Fig. 7. Variation in the numbers of radial currents calculated along the beam line and tide observed at Oura

\section{Cyclic variation in data acquisition}

In the preceding section, we chose the period in which the data acquisition showed extreme decrease. In this section, we focused on the daily variation in data acquisition. The variations in the number of detected radial currents and tide observed at Oura from January 18 to February 1, 2007 are shown in Fig. 7. There was a little rain on January 17 to 18 , which was about $4 \mathrm{~mm}$. In Fig. 7, the number of radial currents shows a cyclic variation synchronised with the variation of tide. Approximately, the number of detected radial currents increases in high tide and adversely decreases in low tide. This cyclic variation does not occur consistently, but we found this variation in other periods and seasons. The ranges of cyclic variation are about 50 at Unzen and about 100 at Arao. The tidal flat in front of Arao may cause a larger variation than that at Unzen because the appearance of the tidal flat in low tide leads to a large propagation loss.

We conducted spectrum analysis using data obtained from December 8, 2006 to April 18, 2007 when there was no heavy rain. Fig. 8 shows the results of spectrum analysis at Unzen. The coherence between the detected current data and the tide indicates a clear peak at about 12.2 hours, which approximately corresponds to the tidal cycle of $\mathrm{M}_{2}$ at 12.4 hours. The phase of 12.2 hours is about 10 degrees. This indicates that the cyclic variation is almost synchronized with the $\mathrm{M}_{2}$ tide.
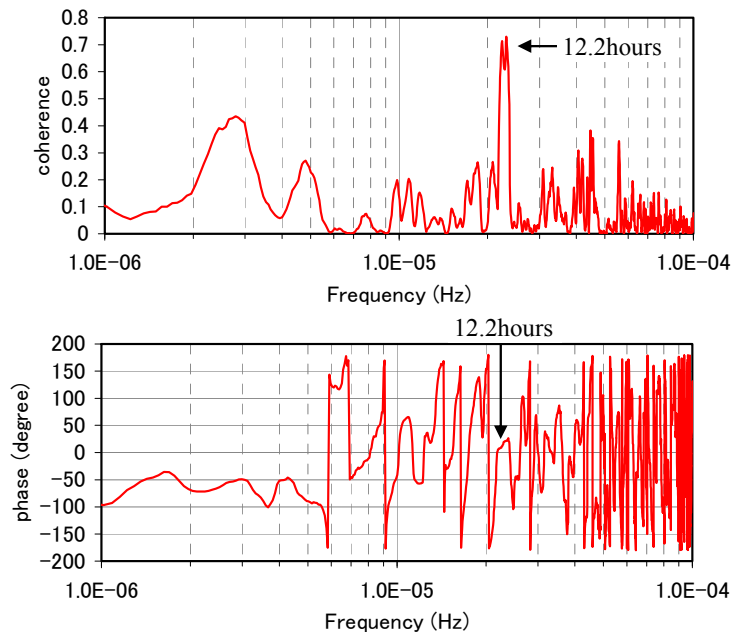

Fig. 8. Result of spectrum analysis between amount of observed data at Unzen and tide at Oura. The coherence and phase are shown.

Fig. 9 shows the variation in the 1st-order scattering of the Doppler spectrum of the beam A6, the tide observed at Oura, and the wind speed observed at the Unzen site on February 19, 2007 when a cyclic variation was notably seen. We confirmed that noise intensity varied little and did not change periodically. In Fig. 9, the cyclic variation is found in the 1storder scattering of the Doppler spectrum in the whole time range. It does not correspond to the variation in wind speed. Additionally, we confirmed that there is no tidal flat around the Unzen site. Thus, the cyclic variation in the 1 st-order scattering intensity is not caused by tidal flats or winds. 


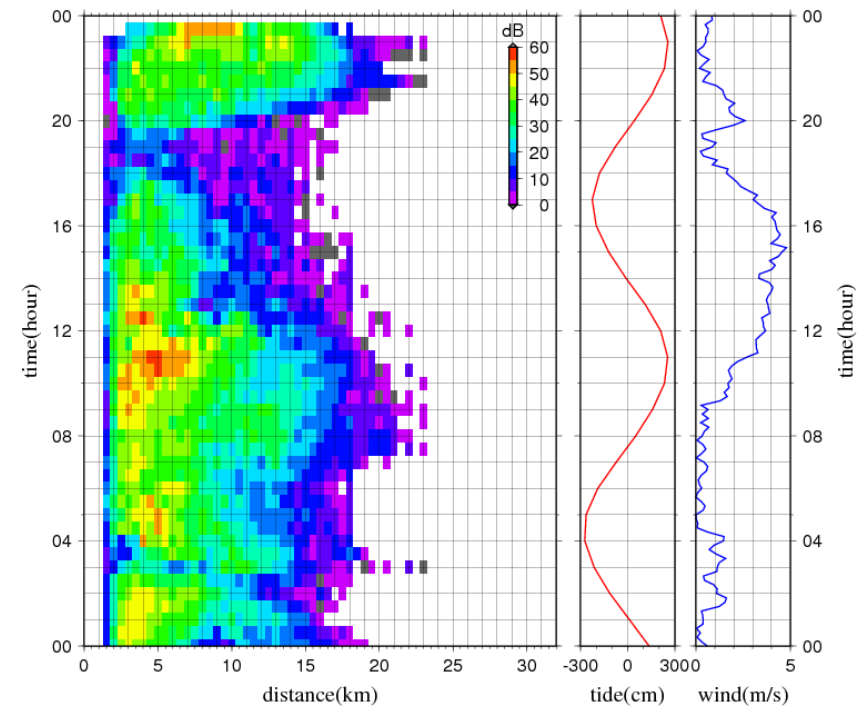

Fig. 9. The variations in 1st order scattering intensity of Doppler spectrum of the beam A6, tide at Oura, and wind speed observed at Unzen from Dec. 19, 2007 to Dec. 20, 2007 (from bottom to top).

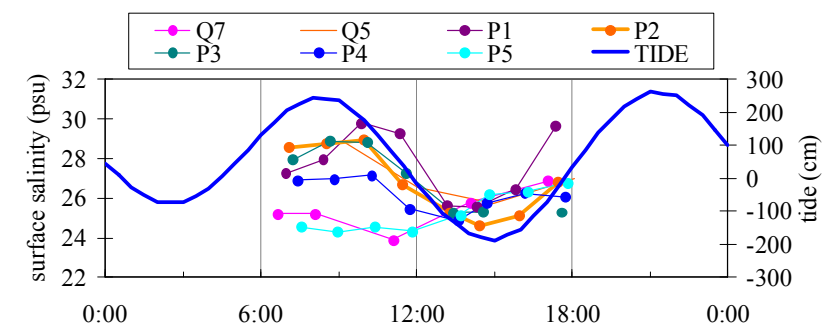

Fig. 10. The variation in surface salinity measured at Aug. 12, 2007 at the spring tide

As mentioned in Chapter II, Ariake Bay and Isahaya Bay have large tidal amplitudes and there is cyclic discharge from the sea dike at Isahaya Bay. These factors might cause a cyclic variation in surface salinity in this area. Fig. 10 shows an example of the variation in the surface salinity measured at the entrance of Isahaya Bay on August 12, 2007. As a result, the surface salinity varied approximately 4 psu in summer, and varied little in autumn. It is unclear whether surface salinity in Ariake Bay varies periodically because the stations of measurement are far from the Chikugo River mouth. Thus, at this moment, we could not determine the effect of salinity on the cyclic variation in the number of the detected radial currents using an ocean radar. The wider observation of surface salinity and the investigation related to other factors such as tidal currents, and the variation of incidence angle due to tide are needed to specify the factor that affect the cyclic variation in detected current data.

\section{DISCUSSION AND CONCLUSIONS}

The purpose of this paper is to investigate the impact factors that affect the observation using an ocean radar. We conducted a field observation at Ariake Bay over one year using a DBF ocean radar with a VHF band. Our study revealed the effect of surface salinity on data acquisition in the sea area by comparing data measured using a radar with surface salinity measured in the observational area of the radar. The effect of surface salinity that decreases receiving intensity is consistent with previous findings obtained through observation with an HF band radar in fresh lakes described in [3]. Additionally, we confirmed that data acquisition immediately follows that of surface salinity in oceans. Secondly, we confirmed the effect of wind speed on the data acquisition. When the wind speed is less than $2 \mathrm{~m} / \mathrm{s}$, the signal intensity decreases with a decrease of wind speed. When the wind speed is over $2 \mathrm{~m} / \mathrm{s}$, the signal intensity varies little because observable waves are fully developed. Moreover, the observational data indicated a cyclic variation with approximately 12 hours synchronised with the $M_{2}$ tide. However, we could not specify the main factor for such variation. A broad range of observations of surface salinity is necessary to identify the influence factor.

From the experimental results, we can conclude the following as regards the observations using a DBF ocean radar with VHF band;

1. A decrease in surface salinity will cause the loss of radio waves, thereby narrowing the observational area.

2. Data acquisition conditions are sensitive to the variation in surface salinity.

3. Wind speed affects the data acquisition, but mainly at very low wind speeds less than $2 \mathrm{~m} / \mathrm{s}$.

4. Observable waves of approximately $3.5 \mathrm{~m}$ wavelength are fully developed for observation when the wind speed is over $2 \mathrm{~m} / \mathrm{s}$.

5. A cyclic variation synchronised with the $\mathrm{M}_{2}$ tide is found in the data variation.

\section{ACKNOWLEDGMENT}

The authors are greatly indebted to Kenta Takenouchi and Shinsaku Someya in Nagasaki University and to Michihiro Mizunuma, Jingo Kaku in West Japan Engineering Consultants Inc. for the help of observation, and to Ken'ich Yamasaki in DCC for development of observation system.

\section{REFERENCES}

[1] S. Sakai, T. Tsubono, M. Matsuyama, and M. Mizunuma, Coastal Current Observation in the Area of Abrupt Topographic Change with $D B F$ Radar, IEEE International Geoscience and Remote Sensing Symposium, pp1852-1855, 2003.

[2] S. Sakai, S. Nishida, A. Tada, M. Matsuyama, and T. Tsubono, Reliability of Horizontal Current Feature Analysis Using DBF Ocean Radar, International Association of Hydraulic Engineering \& Research, 2007

[3] D. M. Fernandez., L. A. Meadows., J. F. Jeffrey, C.C. Teague, J. D. Paduan, and P. Hansen., Surface Current Measurements by HF Radar in Freshwater Lakes, IEEE Journal of Ocean Engineering. Vol. 25, No. 4, pp458-471, Oct. 2000.

[4] T. Tsubono, N. Mori, S. Sakai, M. Matsuyama, Automatic Estimation Method for Surface Currents from Doppler Spectrum Measured by DBF Marine Radar (in Japanese), Proceeding of Coastal Engineering, JSCE, vol. 54, pp. 1446-1450, 2007.

[5] Ministry of Land, Infrastructure and Transport, Japan, Water Information System. [Online]. Available: http://www1.river.go.jp/

[6] Japan Meteorological Agency, Weather, Climate \& Earthquake Information. [Online]. Available: http://www.jma.go.jp/jma/en/menu.html 